DOCUMENT \#3.

DOE/ER/12951--3

DE92 015075

\title{
Public Opinion and Nuclear Power Decision-making
}

\author{
Brien Benson
}

Summary. Public opinion regarding nuclear power is particularly difficult to tie down because of five important paradoxes that characterize it: it can be based on sound reason, but also on intense emotion; it is both national and local in perspective; at varying times it has seen nuclear power as both "clean" and "dirty"; it believes nuclear power is both economic, and uneconomic; and nuclear power is perceived as having a fairly safe record, but being potentially unsafe.

These paradoxes reflect, in part, the nature of nuclear power, but also the diverse and often antagonistic groups that go into forming public opinion. These include industry groups, general interest environmental groups, specifically anti-nuclear groups, governmental agencies and legislatures, academics and analysts, teachers, and journalists.

Equally as complex as the process by which public opinion is formed is the process by which it is converted into public policy. The American political system has numerous checks and balances designed to moderate the power of public opinion. A complex series of legislative, judicial, and executive branch hurdles must be cleared before any idea, however popular, can become day-to-day operating reality in government.

As a result, major changes in policy or programs are difficult, and we may expect that nuclear power will be no different: radical change in one direction or the other is unlikely. Nevertheless, carefully focused programs could achieve modest progress, and carefully designed public opinion surveys could support such programs.

Important, and confusing, paradoxes exist in public attitudes towards nuclear power, the result both of the underlying realities of the nuclear power business, and of the energetic advocacy by diverse groups of often sharply conflicting viewpoints on nuclear power. Five of the most important such paradoxes are as follows:

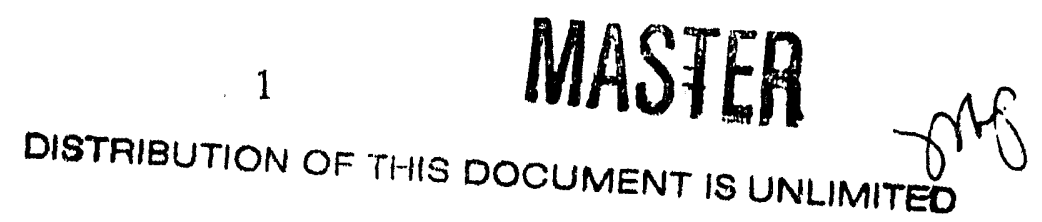


1) Reason vs. emotion. On the one hand, nuclear power is as "high tech" an industrial enterprise as exists, and, as a result, much of the public depends on the consituered judgments of technical experts in formulating opinion on nuclear power. On the other hand, nuclear power can evoke terribly powerful emotional responses, particularly among opponents, that are unresponsive to any rational argument.

2) National vs. local. On the one hand, nuclear power is very much a national issue. It is heavily regulated by the federal government, through the Nuclear Regulatory Commission, and heavily supported by the federal government, through the U.S. Department of Energy and the Tennessee Valley Authority. And the implications for U.S. foreign policy of nuclear proliferation -- particularly of bomb-capable plutonium -- brings the nation's foreign policy-making apparatus into the issue. In these regards, public opinion forms at a national level.

On the other hand, the siting, maintenance, and eventual decommissioning of nuclear power plants, and the siting of nuclear waste disposal locations, are very much issues of local politics, and often bring out strong "NIMBY" (Not in my backyard) sentiments among the public.

3) Environment. On the one hand, nuclear power was initially envisioned, and promoted, as the ultimately clean power source. And, as public awareness grows of the environmenial ill-effects of burning coal to produce electricity (leading to acid rain and global warming), nuclear power may again come to be thought of as the "clean energy". On the other hand, current problems with nuclear waste disposal -- both high-level and low-level -- have given nuclear power a distinctly "dirty" image.

4) Economics. Once billed as a potential source of electric power "too cheap to meter", nuclear power today often evokes images of massive cost overruns, devastating retrospective "prudency" hearings on the wisdom of having built nuclear reactors, up-front capital costs that seem prohibitively high in the face of current interest rates and regulatory delays, and electric power rate hikes when nuclear plants come on line.

Yet opinion surveys show that much of the public believes that the long-run energy needs of the nation will require a healthy nuclear power sector, implying that the public sees the industry's current financial dilemmas as only a transitional problem.

5) Safety. On the one hand, there have been no fatal mishaps during 35 years of nuclear reactor operations in the Western world -- operations that today generate some onefifth of the Free World's electric power. Further, there are no recorded instances of deaths due to uranium mining. Indeed, probably no industrial process in the history of the Western World is as closely regulated for safety as is the generation of nuclear power. By contrast, coal mining, through both accidents and coal dust inhalation, has been responsible for thousands of miners' deaths. 
Notwithstanding the impressive health and safety record of nuclear power, public fears remain substantial. There are several explanations:

-- Nuclear power plant accidents have occurred in the U.S. (TMI and Brown's Ferry), raising the specter of a potential catastrophe, and a catastrophe did occur at Chernobyl.

-- Nuclear power is associated by many with nuclear weapons and, indeed, by some with the bombing of Hiroshima and Nagasaki.

-- Most Americans believe that a nuclear power plant can explode like an atomic bomb.

-- Radiation "leakage" from nuclear power plants or waste disposal sites is associated with cancer, birth defects, premakure aging, and other health hazards.

-- Radiation can "sneak up on you", that is, it cannot be directly perceived by any of the human sense, unlike, for example, coal.

These five paradoxes characterizing public opinion towards nuclear power both influence and are influenced by the public statements, reports, and other activities of diverse groups involved in the nuclear energy debate, including:

-- industry groups, which themselves represent divergent interests;

-- general interest environmental groups;

-- specifically anti-nuclear groups;

-- a welter of governmental agencies and legislative bodies at the federal, state and local levels;

-- academics, consultants, think tanks and others conducting technical and policy research on nuclear power;

-- teachers of science at elementary, secondary, and college levels;

-- journalists, both those with trade publications those with general interest electronic and print media.

Complex as is the process by which public opinion on nuclear power is formed, the 
process by which it, in turn, forms public policy is equally comple.: The authors of our nation's Constitution never intended that public opinion should hold direct and instantaneous sway over the formulation of public policy.

The bicameral legislature; separation of powers among executive, legislative, and judicial branches; and apportioning of authority between the federal and the state governments were all designed, in large part, to prevent a tyranny of the majority, which is to say, a tyranny of public opinion.

Since ratification of the Constitution in the 18th century, additional institutions not even envisioned by the Founding Fathers have arisen that further restrain the power of the majority. These include the press, in all its forms; a firmly established national bureaucracy; diverse special interest groups; and the so-called Iron Triangle, the phenomenon by which a Congressional committee, an executive branch agency, and a Washington lobbying group all dealing with the same issue band together to promote their joint interests in that issue.

Taken together, these institutions and practices, both those created by the Constitution and those created since the Constitution, have come to serve as powerful barriers to major changes in policy and program. Some would call this the genius of American government; others would call it the principal failing of our system.

But, whether bane or blessing, this force for inertia is a fact of life. Once key policies and programs are in place, barring extraordinary external circumstances, an enormous effort is required to mobilize the politicians, the civil service, the policy analysts, the press, the courts, and above all, the public opinion that are required to achieve substantial redirection of any policy.

As applied to nuclear power policy-making, this line of thinking suggests that, as long as the rough "balance of power" that currently exists between nuclear advocates and critics continues -- including the balance in public opinion described above -- we may expect no major change in direction of our nation's nuclear power program.

Spirited battles over regulatory reform, R\&D priorities, siting or decommissioning of particular plants, and waste disposal siting will be fought, with winners and losers. But, overall, we may expect the nation's nuclear power effort to continue at roughly its current level for the immediately foreseeable future.

This is not to say that carefully targeted efforts could not be planned and implemented successfully, whether they be an education program for science teachers, an outreach program to local elected officials, a demonstration program on advanced reactors, or any number of other possibilities. But such programs should have carefully defined, and somewhat limited, objectives.

Such programs could benefit greatly from careful public opinion research, particularly 
if such research has been tailored to the specifics of the program in mind. For example, if there was a notion of, in a decade, replacing certain decommissioned light water reactors with HTGRs, it would be useful to develop a survey for populations in affected areas that directly addressed this issue. Or, if there were thoughts of developing a science education program at the secondary school level, surveys of appropriate teachers, schools boards, and principals could be extremely useful.

Surveys of the general population could also be helpful, if sufficiently focused. One of our interviewees suggested, for example, that the general public be surveyed about its knowledge of how regularly nuclear plants are inspected by the NRC. Such a survey would have the clear purpose of laying the groundwork for a public education program on this particular topic.

\section{\#}

August 6, 1991

\section{DISCLAIMER}

This report was prepared as an account of work sponsored by an agency of the United States Government. Neither the United States Government nor any agency thereof, nor any of their employees, makes any warranty, express or implied, or assumes any legal liability or responsibility for the accuracy, completeness, or usefulness of any information, apparatus, product, or process disclosed, or represents that its use would not infringe privately owned rights. Reference herein to any specific commercial product, process, or service by trade name, trademark, manufacturer, or otherwise does not necessarily constitute or imply its endorsement, recommendation, or favoring by the United States Government or any agency thereof. The views and opinions of authors expressed herein do not necessarily state or reflect those of the United States Government or any agency thereof. 

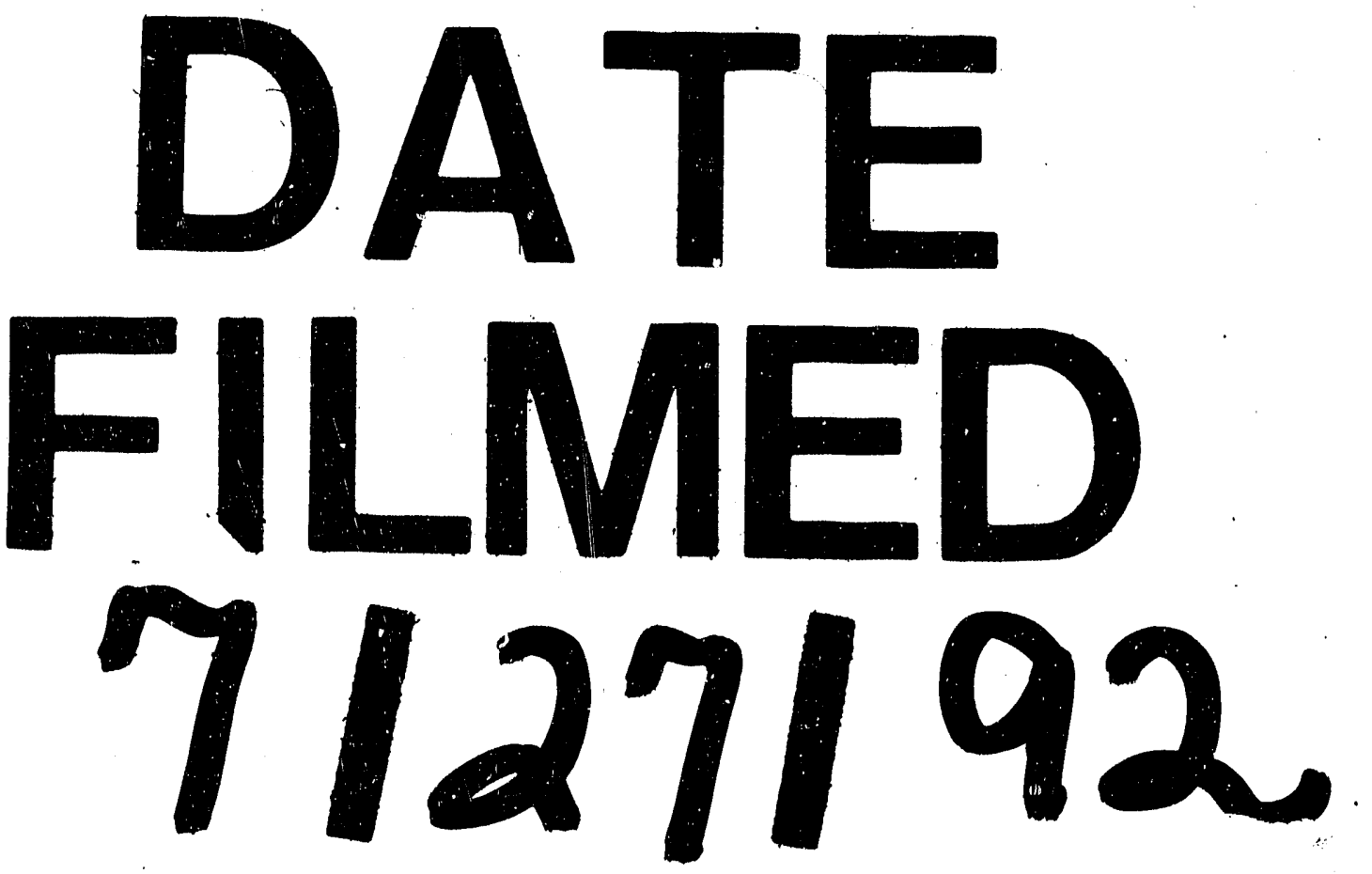
